GU J Sci, Part C, 6(4): 898-908 (2018)

Gazi Üniversitesi
Fen Bilimleri Dergisi
PART C: TASARIM VE TEKNOLOJI
http://dergipark.gov.tr/gujsc

\title{
Rüzgâr Enerjisi Santrali Kurulumunda Rüzgâr Türbinlerinin Mikro Yerleşimi için bir Optimizasyon Modeli
}

\author{
İbrahim ÇELIK ${ }^{1, *}$, Ceyhun YILDIZ ${ }^{1}$, Mustafa ŞEKKELİ \\ ${ }^{I}$ KahramanmaraşS Sütçü İmam Üniversitesi, Elbistan Meslek Yüksekokulu, Elektrik ve Enerji Bölümü, Elbistan /K. Maraş \\ ${ }^{2}$ Kahramanmaraş Sütçü Imam Üniversitesi, Mühendislik Mimarlık Fakültesi, Elektrik Elektronik Mühendisliği Bölümü, Onikişubat/K. Maraş
}

$\ddot{O} z$

\section{Makale Bilgisi \\ Basvuru: $16 / 05 / 2018$ \\ Düzeltme: 19/07/2018 \\ Kabul: 07/08/2018}

Anahtar Kelimeler

Mikro yerleştirme

Rüzgâr Enerji Santrali

Genetik algoritma

WAsP

Weibull dağılımı

\section{Keywords}

Micro-siting

Wind Power Plant

Genetic algorithm

WAsP

Weibull distribution
Rüzgâr enerjisi santrali (RES) kurulumunda rüzgâr türbinlerinin mikro yerleşimi en önemli konulardan biridir. Rüzgâr türbinlerinin uygun şekilde yerleştirilmesi RES'in üretim miktarının artmasını sağlamaktadır. Bu çalışmada 10 adet rüzgâr türbininden oluşan RES kurulumu için bir optimizasyon modeli geliştirilmiştir. Çalışmanın ilk aşamasında RES'in kurulacağı bölgedeki rüzgâr hızı dağılımı modellenmiştir. Bu modelde; RES kurulum sahasından alınmış rüzgâr ölçümleri, RES kurulum bölgesinin topoğrafik haritası ve WAsP (Rüzgâr Atlası Analiz ve Uygulama Programı) yazılımı kullanılmıştır. İkinci aşamada, bölgeye rastgele yerleştirilecek rüzgâr türbinlerinin üreteceği toplam enerji hesabı için genel bir yöntem oluşturulmuştur. Enerji hesaplamasının gerçek üretime yakın olması için rüzgâr türbinine ait gerçek bir güç eğrisi kullanılmıştır. Bu güç eğrisi, 2 MW'lık çıkış gücüne sahip Bonus marka rüzgâr türbinine aittir. Çalışmanın üçüncü aşamasında, Genetik Algoritma (GA) yöntemi kullanılarak optimizasyon modeli çözülmüss ve 10 tane optimal türbin koordinatı belirlenmiştir. Sonuçların değerlendirilmesi amacıyla WAsP yazılımı kullanılarak bu koordinatlara rüzgâr türbinleri yerleştirilmiştir. Yazılımdan alınan sonuçlara göre, rüzgâr türbinlerinin senelik toplam üretimi 56553,5 kWh olarak bulunmuștur. Ayrıca, ortalama rüzgâr hızı haritasında rüzgâr türbini yerleşimlerinin yüksek enerji üretim potansiyeline sahip bölgelere yapıldığ 1 görülmüş̧ür. $\mathrm{Bu}$ sonuç, önerilen modelin RES kurulumunda etkili bir şekilde rüzgâr türbini yerleşimi yaptığını göstermiştir.

\section{An optimization model for wind turbine micro-siting in Wind Power Plant installation}

\begin{abstract}
The wind turbine micro-siting is one of the most important agenda topics in Wind Power Plant (WPP) installations. An appropriate siting of wind turbines increases the amount of energy produced by the WPP. In this study, an optimization model is developed for WPP installation consisting of 10 wind turbines. In the first stage of the study, the wind speed distribution in WPP installation region is modeled. In this model; wind measurements taken from the WPP installation region, topographic map of the WPP installation region and WASP (Wind Atlas Analysis and Application Program) software are used. In the second stage, a general method has been formed for calculating the total energy produced by the wind turbines to be placed randomly in the region. A real power curve belong to the wind turbine is used for the energy calculation to be close to real production. This power curve belongs to the Bonus brand wind turbine, which has an output power of $2 \mathrm{MW}$. In the third stage of the study, the optimization model is solved by using the Genetic Algorithm (GA) method and 10 number optimal turbine coordinates is determined. In order to evaluate the results, wind turbines are placed in these coordinates using WASP software. According to the results from the software, the annual energy production of the wind turbines is found as $56553.5 \mathrm{kWh}$. Furthermore, it has been observed that wind turbine placements are made to the regions, which have high energy production potential in the mean wind speed map. This result showed that the proposed model is placed turbines effectively in WPP installation.
\end{abstract}




\section{GİRIŞ (INTRODUCTION)}

Günümüzde geleneksel enerji kaynaklarının; hızla tükenmesi, çevre ve insan sağlığı üzerinde birçok zararlı etkisinin bulunması yenilenebilir enerji kaynaklarının önemini artırmıştır. Yenilenebilir enerji kaynakları arasında ise rüzgâr enerjisi temiz, çevreci ve kaynak açısından bol olması nedeniyle ön plana çıkmaktadır. Dünyada, rüzgâr enerjisi kullanımı her geçen gün artmaktadır. 2017 y1lı sonu itibariyle dünyadaki rüzgâr türbinlerinin toplam kurulu gücü 539 GW'a ulaşmıştır [1-4].

RES'lerde elektrik enerjisi üretimi, santraldeki rüzgâr türbinleri yardımıyla rüzgârın kinetik enerjisinin elektrik enerjisine dönüştürülmesiyle gerçekleşmektedir. Rüzgâr türbininde üretilen elektrik enerjisi miktarını ise yerel rüzgâr hızı belirlemektedir. Genellikle rüzgâr hızı arttıkça üretilen çıkış gücüde artmaktadır. Bu yüzden RES bölgesindeki yerel rüzgâr hızının olabildiğince yüksek olması istenmektedir [5]. Ancak bunun yanında bir RES üretim miktarı ve maliyeti türbinlerin mikro konuşlandırmasıyla da doğrudan ilişkilidir. Bazen rüzgâr türbinlerinde üretilen güç beklenilenden daha düşük olabilmektedir. $\mathrm{Bu}$ durumun nedeni genelde rüzgâr türbinlerinin en yüksek üretim yapacakları konumlara yerleştirilememesidir. Yanlış yerleşim yapılır ise türbinlere düşük hızda bir rüzgâr ulaşmakta ve bu yüzden üretim düşmektedir [6]-[8]. Üretim düşüşüne engel olabilmek için rüzgâr türbinlerinin yerleşimi en iyi şekilde yapılmalıdır.

RES'lerde rüzgâr türbinlerinin yer tayini için farklı optimizasyon modelleri kullanılmıştır [9]-[12]. Türbinlerin yer tayininde en yaygın olarak kullanılan optimizasyon metotlarından biri GA'dır. Bu konuyla ilgili ilk çalışma Mosetti ve arkadaşları [13] tarafından 1994 yılında gerçekleştirilmiştir. Bu çalışmada oluşturulan amaç fonksiyonu ile maksimum enerji üretimi ve minimum yatırım maliyeti belirlenmeye çalışılmıştır.

Günümüze kadar rüzgâr türbinlerinin mikro yerleştirilmesiyle ilgili yapılmış önemli çalışmalar incelendiğinde [11-25], bu çalışmalarda RES enerji üretiminin rüzgâr hızı olasılık yoğunluk fonksiyonu (Weibull eğrisi) kullanılarak hesaplandığı görülmektedir [14-15]. Weibull eğrisinde kullanılan k şekil parametresi 2 ile 2,4 arasında, ölçek parametresi A ise 5 ile $12 \mathrm{~m} / \mathrm{s}$ arasında konuma göre değişkenlik göstermektedir [16-20]. Bunun yanında RES'deki her türbinde enerji üretimi rüzgâr hızının kübik bir fonksiyonu olarak değişmektedir. Gerçekleştirilen çalışmalarda bu rüzgâr hızı - güç dönüşümü genelde teorik olarak [19-24] çok az çalışmada ise deneysel olarak $[18,19,26]$ hesaplanmıştır. Bu çalışmada rüzgâr hızı olasılık yoğunluk fonksiyonu hesaplanırken diğer yapılan çalışmalardan farklı olarak A ve $\mathrm{k}$ parametreleri WAsP yazılımı kullanılarak elde edilmiştir. Bunun yanı sıra rüzgâr hızı - güç dönüşümünün deneysel sonucu olan türbin güç eğrisi kullanılarak daha gerçekçi bir sonuç ortaya koyulmuştur. Ayrıca gerçekleştirilen modelin GA ile çözümünün etkinliği WAsP ortalama rüzgâr hızı haritasına rüzgâr türbinleri yerleştirilerek incelenmiştir.

Bu çalışma üç bölümden oluşmaktadır. İlk bölümde RES'in kurulum modeli incelenmiştir. İkinci bölümde modelin çalıştırılması sonucu elde edilen sonuçlar sunulmuş ve bu sonuçlara göre WAsP ortalama rüzgâr hızı haritasına bir RES kurulumu gerçekleştirilmiştir. Son bölümde ise kurulmuş olan RES'deki türbinlerin yerleşimi incelenerek elde edilen sonuçlar tartışılmıştır.

\section{RES KURULUM MODELİ (WPP INSTALLATION MODEL)}

Rüzgâr türbinlerini yerleştirme işleminde iki temel problem ortaya çıkmaktadır. Bunlardan ilki belirlenen bölgeye kaç adet türbinin yerleştirileceğini belirlemektir. İkincisi de bu türbinlerin enerji üretimlerinin en yüksek olacağı konumları bulmaktır. Bu şekilde RES kurulumu gerçekleştirilerek, türbinlerdeki üretim kaybı minimize edilebilmektedir. Bu yüzden RES kurulumunda bu konu önemli bir hale gelmiştir [27].

$\mathrm{Bu}$ bölüm dört kısımdan oluşmaktadır. Bunlardan ilki rüzgâr yön ve yoğunluğu modelinin oluşturulmasıdır. İkincisi türbinleri yerleştirmek için belirlenen karesel alanlarda Weibull olasılık yoğunluk fonksiyonuna göre yıllık enerji üretiminin hesaplanmasıdır. Üçüncüsü türbinleri yerleştirmek için kullanılan kısıt ve amaç fonksiyonlarıdır. Son kısım ise gerçekleştirilmiş olan enerji üretim modelinin GA ile çözülmesidir. 


\subsection{Rüzgâr Yön ve Yoğunluğu (Wind Direction and density)}

Rüzgâr yön ve yoğunluğu bazı etkenlere bağımlı olarak değişiklik göstermektedir. Yeryüzünde yükseklere çıkıldıkça rüzgâr hızı artmaktadır. Bu genellikle logaritmik kuralı ya da güç kuralıyla modellenmektedir [15]. Bu çalışmada incelenen bölge için her sektörün rüzgâr hızları ve yüzde olarak rüzgâr hızlarının frekans dağılımları WAsP yazılımından Şekil 1'deki gibi elde edilmiştir. Şekildeki grafikte $0^{\circ}-360^{\circ}$ arasında değişen yön değerleri $30^{\circ}$ 'lik 12 sektöre ayrılmıştır. Her sektördeki; ortalama rüzgâr hızı sağdaki renk skalası ile, tekrar sayısı ise yüzde olarak verilmiştir.

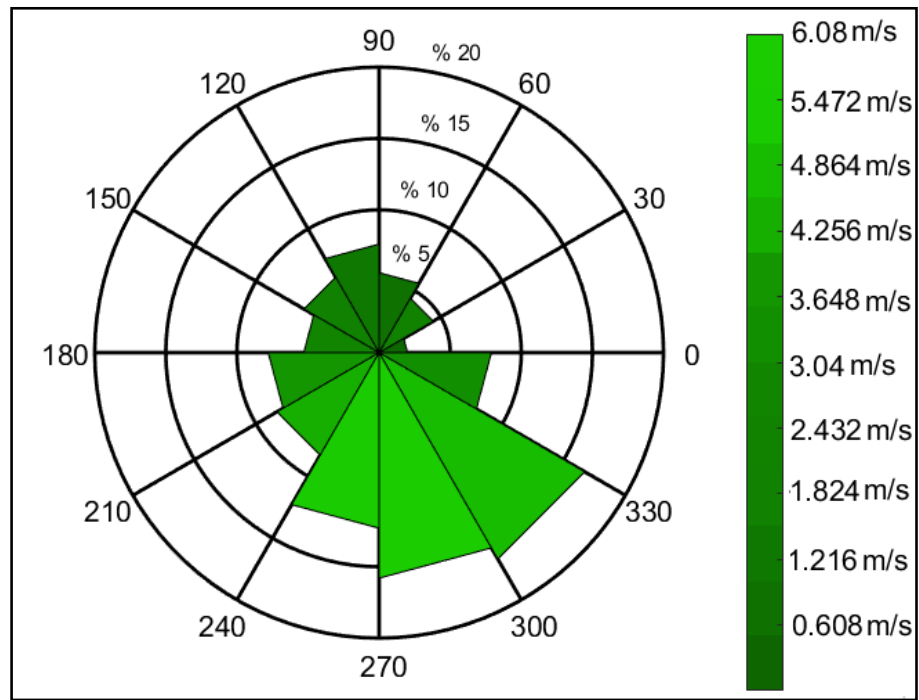

Şekil 1. Her sektör için rüzgâr hızları ortalamaları ve yüzde olarak rüzgâr hızlarının frekans dağllımları

\subsection{Weibull Olasılık Yoğunluk Fonksiyonu Kullanılarak Yıllık Enerji Üretiminin Hesaplanması (Calculation of Annual Energy Production Using Weibull Probability Density Function)}

RES Danimarka Roskilde bölgesine kurulmuştur. RES kurulumu için belirlenmiş bölgeye 10 adet 2 MW'lık Bonus marka rüzgâr türbini yerleştirmek istenmektedir. RES'in kurulumunda kullanılmış olan amaç fonksiyonunda, yatay eksen (x) ve dikey eksen (y) olarak kabul edilmiştir. Bu tanıma göre $\mathrm{x}$ ekseni ve y ekseni 20 eşit uzunlukta parçaya bölünerek 400 adet karesel alan elde edilmiştir. Bu 400 karesel alandan her biri için türbinlerin üretim değerleri bulunarak buna göre türbin yerleştirme işlemi gerçekleştirilmiştir. Bu işlem için ilk olarak rüzgâr hızı $v_{i}$ için 2 parametreli (k ve $A$ ) Weibull olasılık yoğunluk fonksiyonu Denklem 2.1'deki gibi ifade edilmiştir. Burada $f\left(v_{i}\right)$ gözlemlenen rüzgâr hızı $v_{i}$ 'nin olasılık fonksiyonunu, $\mathrm{k}$ ile A ise sırasıyla şekil ve ölçek parametrelerini ifade etmektedir . RES kurulumu için belirlenen bu bölgede Weibull olasılık yoğunluk fonksiyonunu hesaplamak için her bir karesel alanın A ve k parametreleri WAsP yazılımından elde edilmiştir. Bu parametrelerin değişimleri ise Şekil 2 ve Şekil 3'te gösterilmiştir.

$$
f\left(v_{i}\right)=(k / A)\left(v_{i} / A\right)^{k-1} e^{-\left(\frac{v_{i}}{A}\right)}
$$

Şekil 2'de ifade edilmiş olan k şekil parametresi boyutsuz olup belirlenmiş olan bölgede 2,27 ile 2,53 arasında değişmektedir. Weibull olasılık yoğunluk fonksiyonunda sadece $\mathrm{k}$ parametresinin değişken olması kaydıyla, değişik $\mathrm{k}$ değerlerine göre farklı eğriler elde edilebilmektedir. Bu değişim $\mathrm{k}$ değerinin artmasına karşılık eğrinin tepe noktasının daha dik bir hale gelmesi şeklinde ifade edilir. Bu durum bölgede daha düşük rüzgâr hızı değişimi olduğunu göstermektedir.

Şekil 3'te verilen A ölçek parametresi $7 \mathrm{~m} / \mathrm{s}$ ile $8,5 \mathrm{~m} / \mathrm{s}$ arasında değişmektedir. Weibull olasılık yoğunluk fonksiyonunda sadece A parametresinin değişken olması kaydıyla değişik A değerlerine göre farklı eğriler elde edilebilmektedir. A ölçek parametresinin artışına bağlı olarak eğri yatay eksene uzanmakta ve yüksekliği düşmektedir. Bu da bölgede yüksek rüzgâr hızı değişimi olduğunu ifade etmektedir [28-30]. 


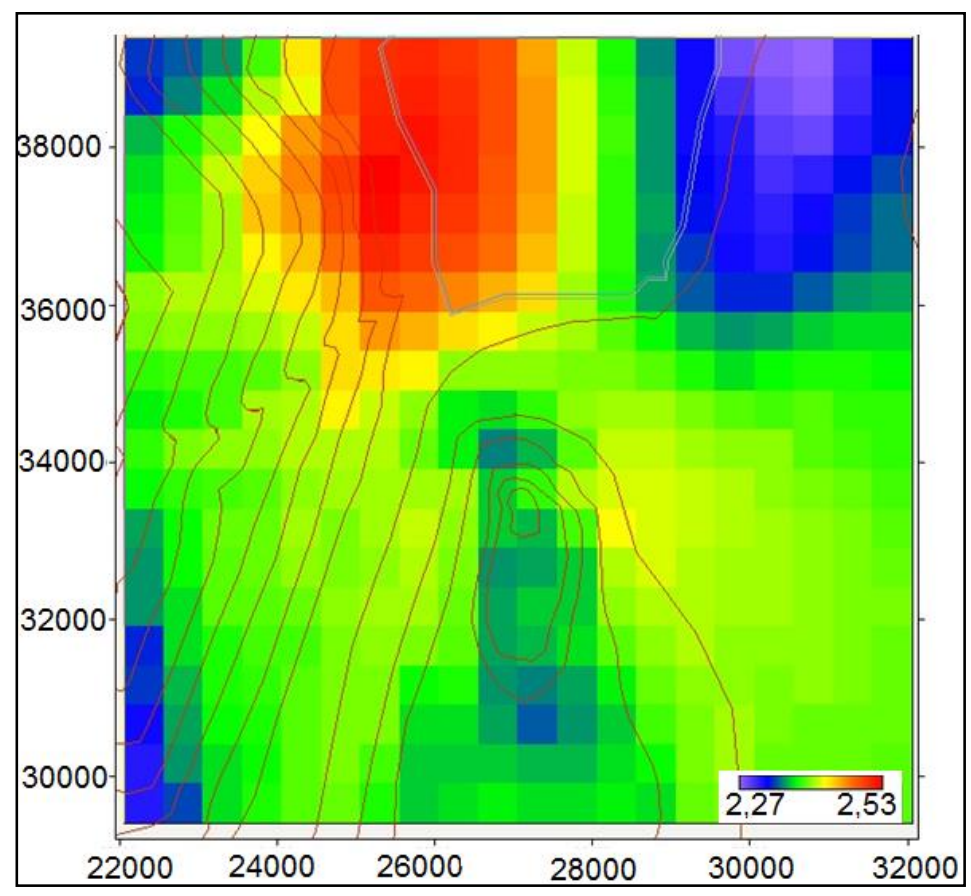

Şekil 2. RES kurulumu için belirlenmiş bölgede k parametresinin değişimi.

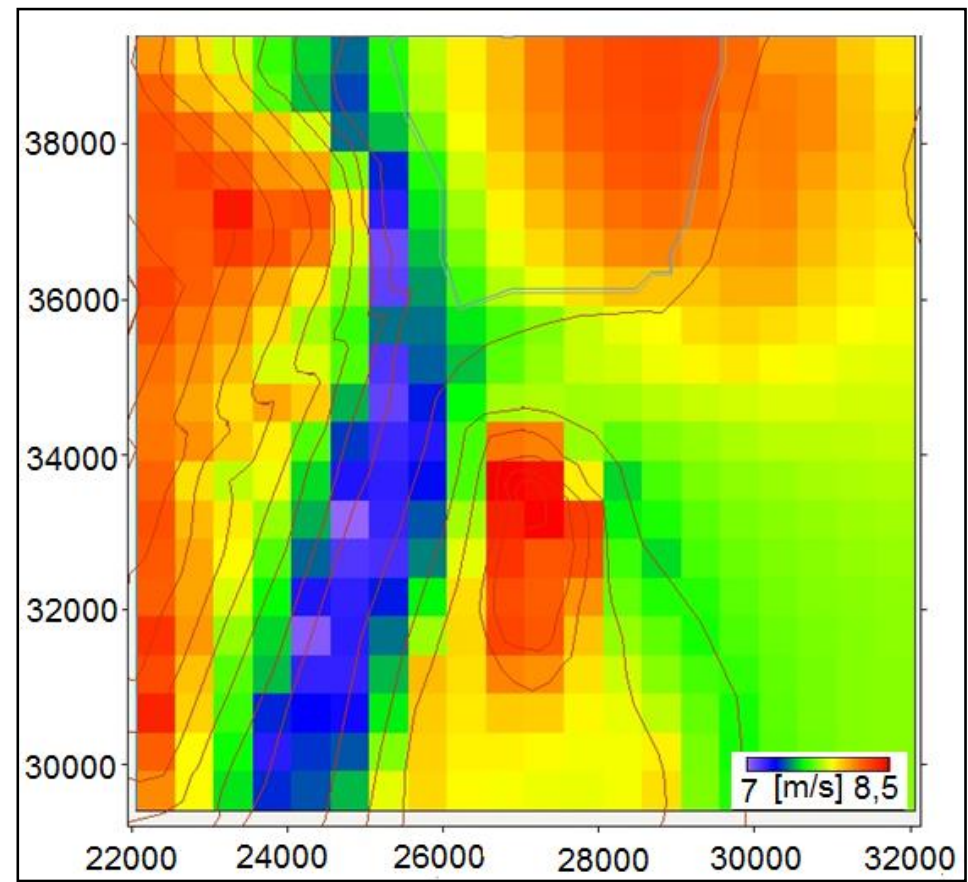

Şekil 3. RES kurulumu için belirlenmiş bölgede A parametresinin değişimi.

RES kurulumu için belirlenen bölgede hem $\mathrm{A}$ hem de $\mathrm{k}$ parametresi her karesel alan için değişken değerlere sahiptir. Bu değerler kullanılarak tüm karesel alanların Weibull olasılık yoğunluk fonksiyon değeri hesaplanmıştır. Bu sayede herhangi bir karesel alana türbin yerleştirilmesi durumunda her bir türbin için yıllık enerji üretimi Denklem 2.2 kullanılarak elde edilmiştir.

$$
\text { YEÜ }=8760\left[\int_{V_{c i}}^{V_{c o}} f\left(v_{i}\right) P\left(v_{i}\right) d v_{i}\right]
$$

Denklem 2.2'de $\mathrm{V}_{\text {ci }}$ rüzgâr türbininin devreye girdiği hızı, $\mathrm{V}_{\text {co }}$ ise rüzgâr türbininin devreden çıktığı hızı ifade etmektedir. $\mathrm{P}\left(\mathrm{v}_{\mathrm{i}}\right)$ ise türbin güç eğrisinden elde edilen türbinin $\mathrm{v}_{\mathrm{i}}$ hızında ürettiği güç değeridir. Bir 
rüzgâr türbini için yıllık enerji üretimi hesaplanırken türbinin hız değeri, türbinin devreye girdiği hız ile devreden çıktığı hız değeri arasında birer birimlik aralıkların orta noktası alınarak hesaplanmıştır.

Türbinin hız- güç eğrisi ve itki katsayısı $(\mathrm{Ct})$ Şekil 4'te verilmiştir. Şekil 4'e göre türbinimiz $3 \mathrm{~m} / \mathrm{s}$ hıda devreye girmekte, $25 \mathrm{~m} / \mathrm{s}$ hıza kadar üretim gerçekleştirmekte ve $25 \mathrm{~m} / \mathrm{s}^{\prime}$ den sonra devreden çıkmaktadır. Ancak $15 \mathrm{~m} / \mathrm{s}^{\prime}$ den sonra türbin üretim değeri yaklaşık olarak $2 \mathrm{MW}$ olmaktadır. Türbinin Ct değeri ise hız ile çıkış gücünün doğrusal olarak arttığı bölgelerde yüksek iken, hız artışına karşılık çıkış gücünün artışının daha az olduğu bölgelerde daha düşüktür. Ayrıca türbinin bazı karakteristik özellikleri ise Tablo 1'de özetlenmiştir [31].

Tablo 1. 2MW Bonus rüzgâr türbini karakteristik özellikleri

Göbek yüksekliği (m) 60

Rotor çapı (m) 76

Devreye girme hızı $(\mathrm{m} / \mathrm{s}) \quad 3$

Devreden çıkma hızı $(\mathrm{m} / \mathrm{s}) \quad 25$

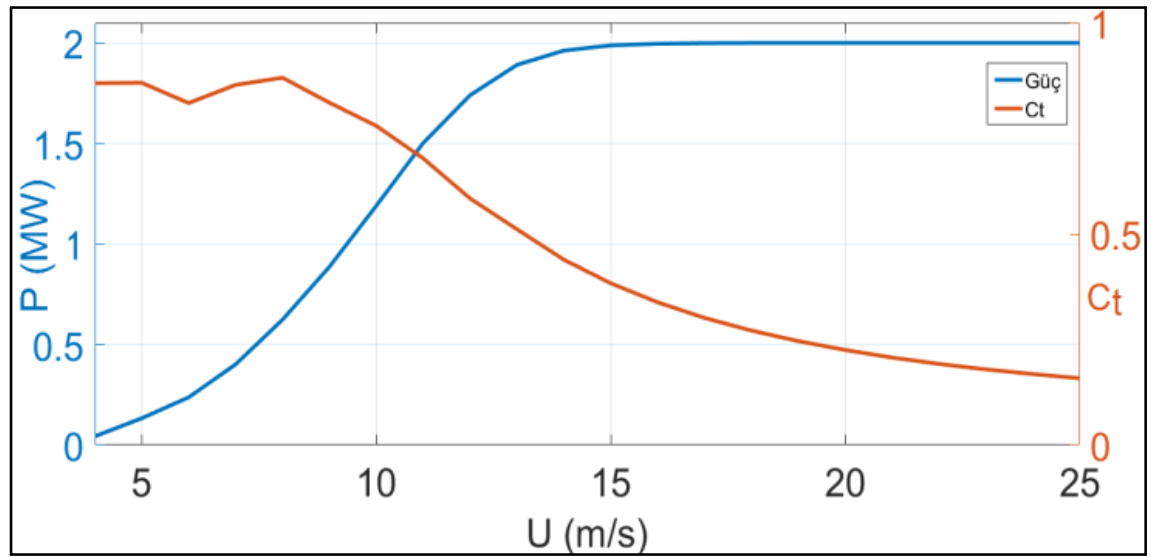

Şekil 4. 2 MW Bonus Türbin Hız güç eğrisi ve kapasite faktörü.

\subsection{Rüzgâr Türbini Yerleştirmek için Kullanılan Optimizasyon Modeli (Optimization Model Used for Wind Turbine Placement)}

Bir RES'te rüzgâr türbinlerinin ürettikleri enerji miktarının olabildiğince yüksek seviyede, yatırım maliyetinin ise olabildiğince düşük seviyede olması istenmektedir. Bu durum göz önüne alınarak Nt adet türbinin yıllık üretim değeri Denklem 2.3'te ifade edilmiştir. Bunun yanı sıra bir RES'in yıllık maliyeti Denklem 2.4'te verilmiştir [13].

$$
\begin{array}{r}
P_{\text {RES }}=\sum_{\mathrm{i}=1}^{\mathrm{i}=\mathrm{N}_{\mathrm{t}}} 8760\left[\int_{\mathrm{V}_{\mathrm{ci}}}^{\mathrm{V}_{\mathrm{co}}} \mathrm{f}\left(\mathrm{v}_{\mathrm{i}}\right) \mathrm{P}\left(\mathrm{v}_{\mathrm{i}}\right) \mathrm{dv}_{\mathrm{i}}\right] \\
\mathrm{C}_{\text {RES }}=N_{t}\left(\frac{2}{3}+\frac{1}{3} \mathrm{e}^{-0.00174 \mathrm{~N}_{\mathrm{t}}{ }^{2}}\right)
\end{array}
$$

Amaç fonksiyonu, kWh başına üretilen enerjinin maliyetini düşürerek yıllık faydayı maksimize etmek şeklinde ifade edilebilir. Böylece amaç fonksiyonu ifadesi Denklem 2.5’teki gibi olur.

$$
\operatorname{amaç}=\left(\frac{C_{R E S}}{P_{R E S}}\right)
$$

Burada $\mathrm{C}_{\mathrm{RES}}$ bir RES'in yıllık maliyetidir. $\mathrm{P}_{\mathrm{RES}}$ ise bir RES'in senelik toplam üretimini ifade etmektedir. 


\subsection{Genetik Algoritma ile Çözüm (Solution with Genetic Algorithm)}

GA doğadaki evrim mekanizmasını örnek alınarak oluşturulmuştur. İçerisinde evrimsel hesaplama tekniği sayesinde doğal seleksiyon ve en güçlü olanın hayatta kalma becerisi birleştirilip modellenebilmektedir. GA, bireysel çözüm adaylarının değerlendirilmesi için yeniden formüle edilmeyi gerektirmeden karmaşık sorunlar için etkili bir çözüm bulma yeteneğine sahiptir. Doğal üreme sürecinde olduğu gibi, iki kişiden oluşan bir kromozomal dizide depolanan genetik bilgi, yeni bir bireyin genetik kodunu oluşturmak için kullanılır. Türlerde evrim ve adaptasyon, en iyi olan bireylerin hayatta kalma ve çoğalma olasılıklarının en yüksek olmasını garanti etmektedir. GA'da neyin en iyi olduğunu bildirmek içinse bir uygunluk (amaç) fonksiyonu oluşturulmalıdır. Oluşturulan uygunluk (amaç) fonksiyonu ve problemin değişkenlerinin kodlanmasıyla, problemin çözümü kolaylıkla gerçekleştirilebilmektedir [32].

GA ile optimizasyon işleminde her türbinin konumu bir geni, 10 adet gen ise bir bireyi yani RES'i ifade etmektedir. Optimizasyon işleminde rastgele bir RES konum popülasyonundan başlanarak, nüfusun her bir bireyinin enerji üretim değeri daha önce açıklanan RES'in kurulum modeli aracılığıla değerlendirilmekte ve enerji üretim değerine göre sonraki nesil oluşturulmaktadır. Bu süreçte, en iyi çözüm, evrimin ilk evrelerinde bile bulunabilmektedir. Bununla birlikte, nüfusun ortalama enerji üretim değeri arttıkça, en güçlü birey muhtemelen en gelişmiş nüfusun bir parçası olmaktadır. Bu şekilde GA ile optimizasyon işlemi gerçekleştirilerek rüzgâr türbinlerinin konumları optimal bir şekilde bulunmaktadır. GA ile çözüm, işlem basamakları halinde Şekil 5'te verilmiştir.

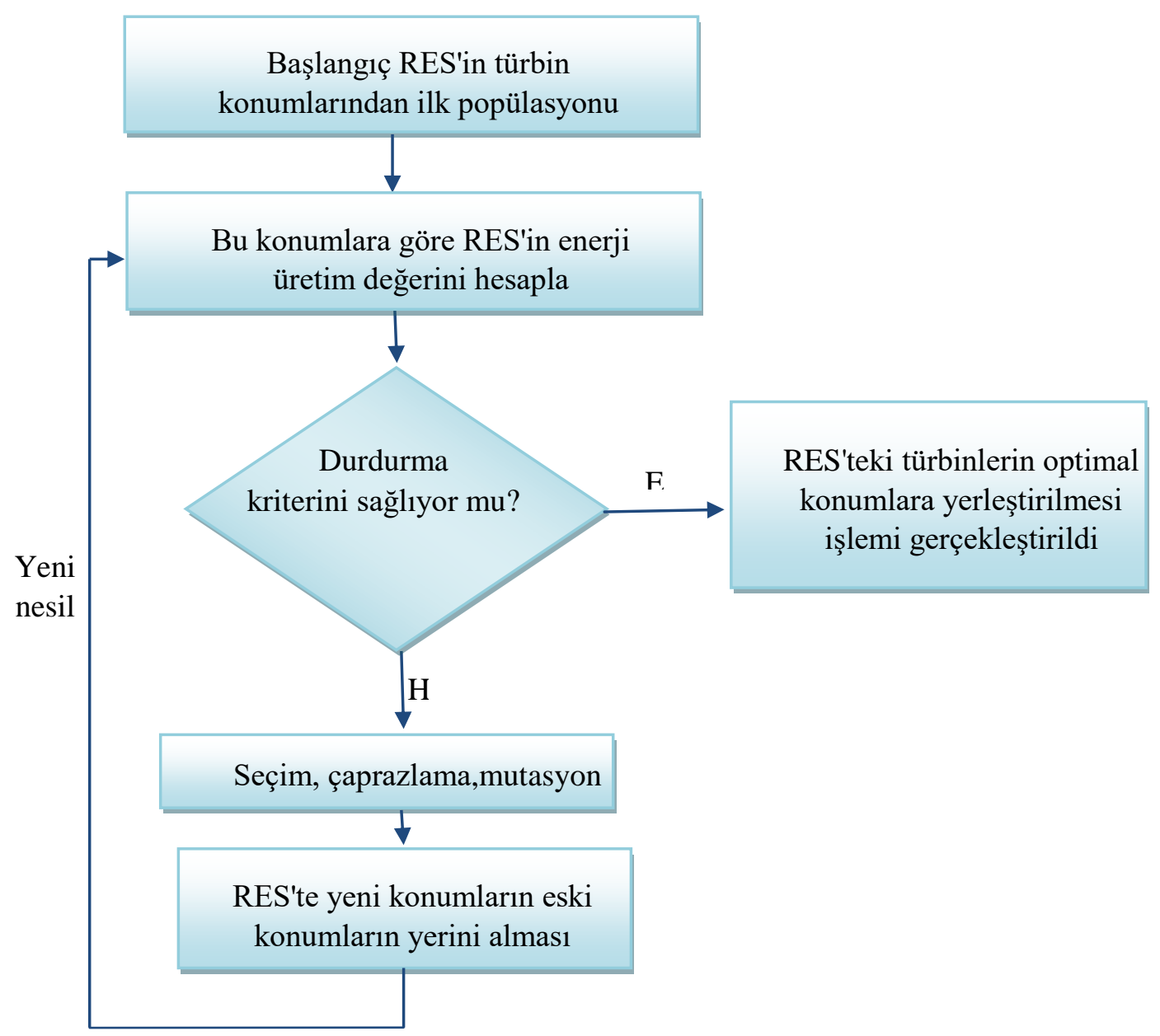

Şekil 5. Genetik algoritmanin işlem basamakları. 
Şekil 5 'teki ifade edilmiş olan süreçte türbinlerin üst üste konulmaması için türbin yerleşiminde Denklem 2.6, 2.7 ve 2.8 'deki kısıtlar göz önüne alınmıştır.

$$
\begin{array}{r}
\sqrt{\left(X_{i}-X_{i+1}\right)^{2}+\left(Y_{j}-Y_{j+1}\right)^{2}}>0 \\
1 \leq \mathrm{i} \leq 10 \forall \mathrm{i} \in \mathrm{N} \\
1 \leq \mathrm{j} \leq 10 \forall \mathrm{j} \in \mathrm{N}
\end{array}
$$

Bu kısıtlardan 2.7 ve 2.8 'de 10 adet türbin yerleşimi yapacağımız için i ve j değerleri 1'den 10 'a kadar tanımlanmakta ve 2.9 'da ise yerleştirilmiş olan bir türbinin konumuyla diğer türbin konumları arasındaki uzaklık değerinin her zaman 0'dan büyük olması istenmektedir.

\section{ARAȘTIRMA BULGULARI VE TARTIȘMA (RESEARCH RESULTS AND DISCUSSION)}

$\mathrm{Bu}$ çalışmada WAsP yazılımından belirlenen bir bölgeye RES kurulumu gerçekleştirilmiştir. RES kurulumu için belirlenen bölgedeki arama uzayı arttıkça bu işlem zorlaşacağı için GA kullanılmıştır. Bu işlem sırasında amaç fonksiyonunda ifade edilmiş olan $\mathrm{P}_{\mathrm{RES}}$ değeri, türbinlerin gölgeleme etkisinin olmadığı durum göz önüne alınarak hesaplanmıştır. $C_{\text {RES }}$ değeri ise türbin sayısının sabit olduğu kabul edilerek yıllık maliyet değeri sabit alınmıştır. GA ile hesaplama işleminde RES'in en yüksek üretim gerçekleştirilebileceği 10 adet karesel alan belirlenmiştir. Burada 2.7, 2.8 ve 2.9'da ifade edilmiş olan kısıtlar göz önüne alınarak gerçekleştirilen optimizasyon sonucunda 50 birey için ortalama ve en iyi üretim değeri Şekil 6'da verilmiştir. En iyi üretim değerini oluşturan bireyin konumları ise Şekil 7'de gösterilmiştir. Şekil 7'de ifade edilen en iyi bireyin konumlarından ilk 10 değer sırasıyla y koordinatlarını, son 10 değer ise sırasıyla $\mathrm{x}$ koordinatların ifade etmektedir. Bu şekilde elde edilen koordinatlar ise Tablo 2 'de verilmiştir.

Ortalama rüzgâr hızı haritasında Tablo 2'de verilen koordinatlara türbinler yerleştirilmiştir. Bu yerleşim Şekil 8'de gösterilmiştir. Bu haritadaki veriler, türbin kule yüksekliği için türbin koordinatında hesaplanan düşey serbest atmosfere dik doğrultuda esen rüzgârın ortalama hızını ifade etmektedir. RES kurulumu gerçekleştirilmiş olan bölgede ortalama rüzgâr hızı $6,16 \mathrm{~m} / \mathrm{s}$ ile $7,49 \mathrm{~m} / \mathrm{s}$ arasında değişmektedir.

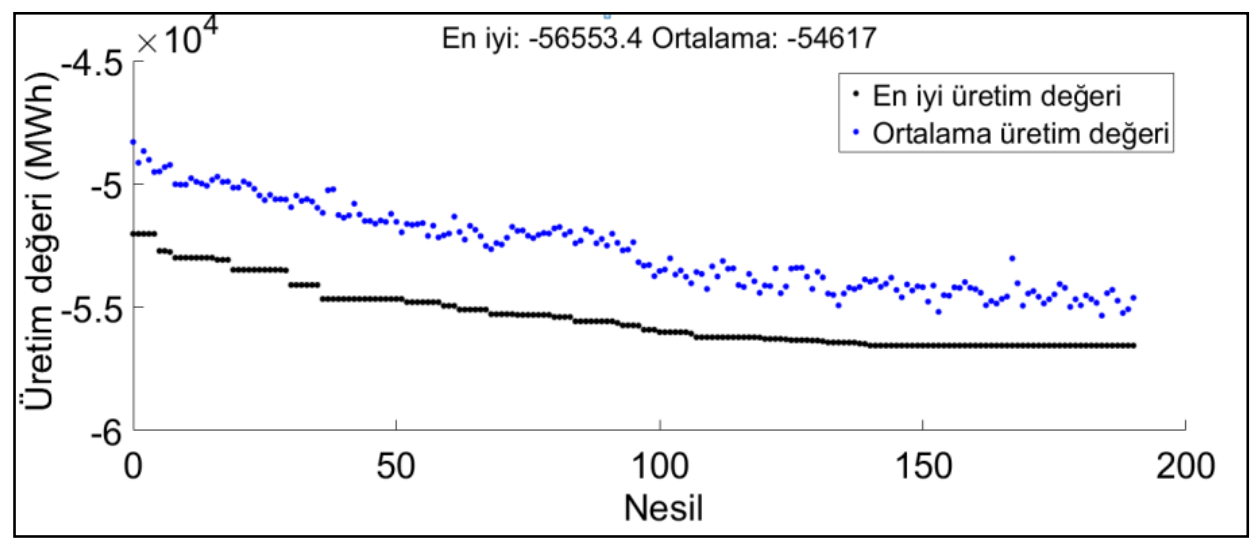

Şekil 6. RES'in en iyi üretim değerinin bulunmast. 


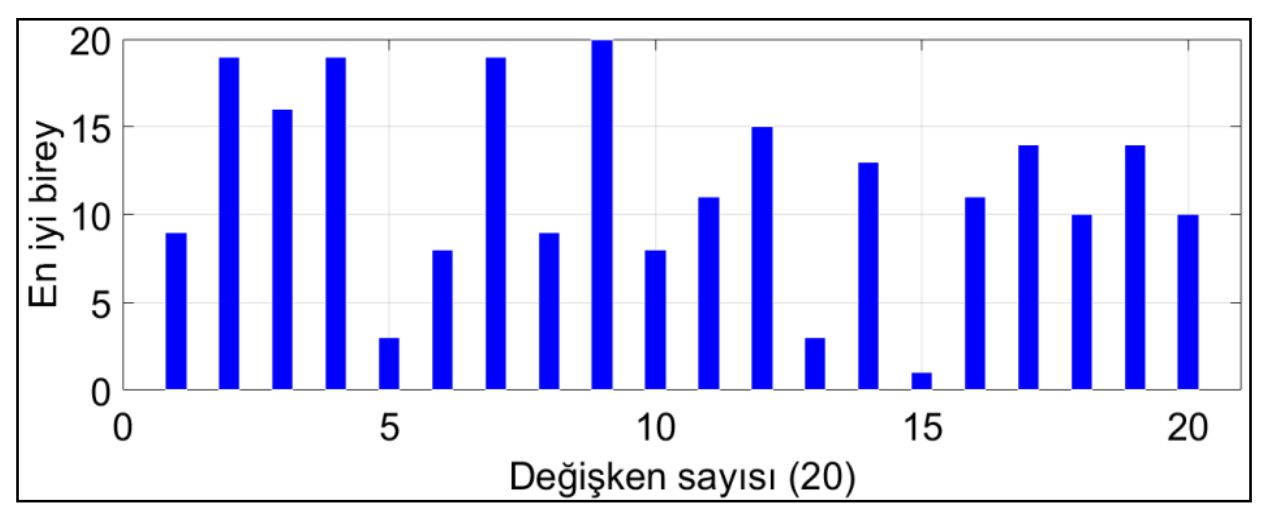

Şekil 7. En iyi üretim değerine sahip bireyin konumlart.

Tablo 2. Türbinlerin yerleştirilecekleri koordinatlar.

\begin{tabular}{ccccccccccc}
\hline Yerleşim koordinatları & 1. & 2. & 3. & 4. & 5. & 6. & 7. & 8. & 9. & 10. \\
\hline Y & 9 & 19 & 16 & 19 & 3 & 8 & 19 & 9 & 20 & 8 \\
$\mathrm{X}$ & 11 & 15 & 3 & 13 & 1 & 11 & 14 & 10 & 14 & 10 \\
\hline
\end{tabular}

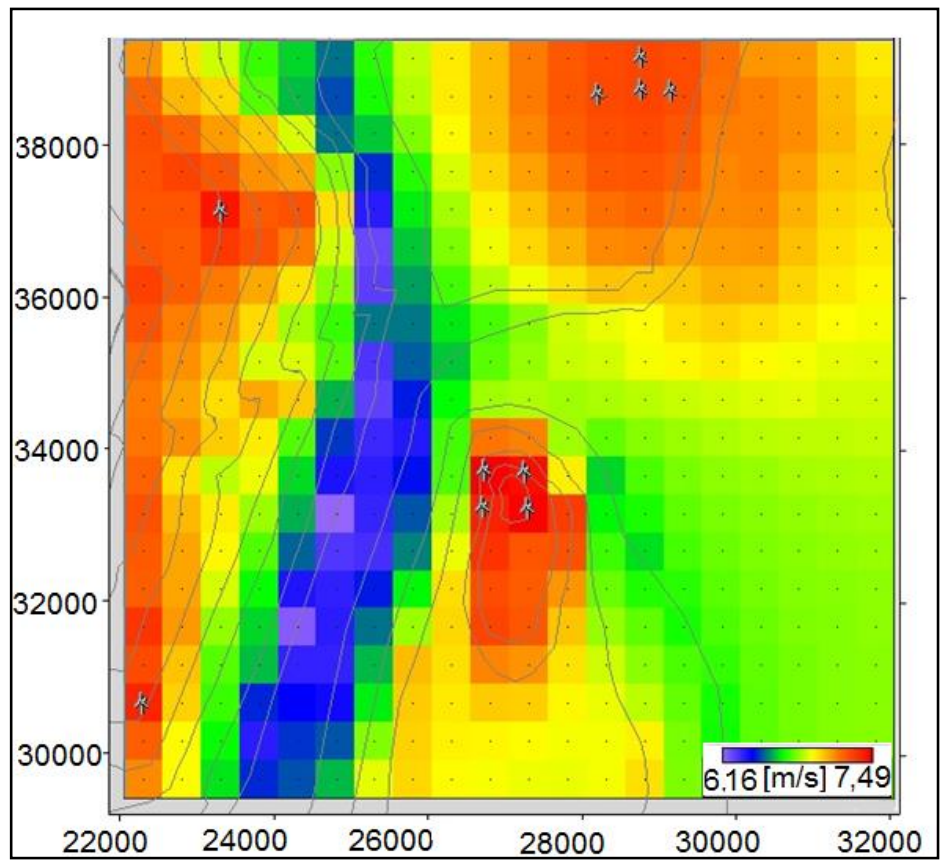

Şekil 8. Ortalama rüzgâr hızı haritasina RES kurulumu.

\section{SONUÇ (CONCLUSION)}

RES kurulumunda rüzgâr türbinlerinin yerleşimi RES'in üretim potansiyelini etkilemektedir. Bu yüzden RES kurulumu gerçekleştirilirken RES'in üretimin potansiyelinin en yüksek olmasını sağlayan konumlara türbinlerin yerleşimi yapmak büyük öneme haizdir.

Bu çalışmada bir RES kurulumunda rüzgâr türbinlerinin mikro yerleşimi için bir optimizasyon modeli sunulmuştur. Bu süreçte öncelikle RES kurulum modeli oluşturulmuştur. Bu modelde RES kurulumu yapılacak bölge $20 \times 20$ adet karesel alanlara bölünmüştür. Türbin yerleşimi için uygun olan her karesel alanın muhtemel enerji üretim değerleri hesaplanmıştır. Bu hesaplamada Weibull olasıllk yoğunluk fonksiyonu ve türbin güç eğrisi kullanılmıştır. Weibull olasılık yoğunluk fonksiyonu, WAsP yazılımından elde edilmiş olan A ve k parametreleri yardımıyla hesaplanmıştır. Ayrıca rüzgâr hızı - güç dönüşümü için türbinlerin deneysel olarak elde edilmiş güç eğrisi kullanılmıştır. RES enerji üretim modelinin çözümü, 
GA ile gerçekleştirilmiştir. Daha sonra RES kurulumu için belirlenmiş olan bölgenin WAsP yazılımından ortalama rüzgâr hızı haritası elde edilmiştir. Bu haritada, GA ile çözüm sonucunda elde edilmiş olan koordinatlara rüzgâr türbinleri yerleştirilmiştir. Son olarak da bu işlem sonucunda rüzgâr türbinlerinin yerleştirilmiş oldukları konumlar incelenmiştir. Bu belirtilen süreç, RES kurulum modelinde kullanılmış olan WAsP yazılımının ve deneysel türbin güç eğrisinin santral kurulumunda etkili bir sonuç verdiğini göstermiştir. GA ile gerçekleştirilen çözümde ise yüksek enerji üretim potansiyeline sahip olan karesel alanlara rüzgâr türbinleri yerleştirildiği görülmüştür. Bu sayede RES'in üretim potansiyeli artırılmaya çalışılarak kWh başına maliyet minimize edilmiştir. Bu modelin uygulaması Danimarka Roskilde bölgesinde yapılmıştır. Bu bölgede kurulan RES'te 10 adet rüzgâr türbini kullanılmıştır. GA ile çözümde türbinlerin konumları değiştirilerek RES'in yıllık enerji üretimi $52000 \mathrm{kWh}$ dolaylarından 56553,5 kWh'a kadar artırıldığı görülmüştür. Bu çözüm sonucunda bulunan türbin koordinatları incelendiğinde, rüzgâr hızının 7,49 m/s'ye yakın olduğu karesel bölgelere rüzgâr türbinlerinin yerleştirildiği belirlenmiştir.

Bu çalışmadan sonra gerçekleştirilecek olan çalışmalarda bu model geliştirilerek gerçek bir RES’te rüzgâr türbinlerinin optimal yerleşiminde kullanılabilir. Ayrıca farklı optimizasyon algoritmalarıyla bu modelin çözümü gerçekleştirilerek GA'nın performansıyla kıyaslanabilir.

\section{NOMENKLATÜR (NOMENCLATURE)}

$\begin{array}{lll}\mathrm{f}\left(\mathrm{v}_{\mathrm{i}}\right) & =\mathrm{v}_{\mathrm{i}} \text { rüzgâr hızı olasılık yoğunluk fonksiyonu } & (\text { Birimsiz) } \\ \mathrm{v}_{\mathrm{i}} & =\text { Rüzgâr hızı } & (\mathrm{m} / \mathrm{s}) \\ \mathrm{K} & =\text { Sekil parametresi } & (\text { Birimsiz }) \\ \mathrm{A} & =\text { Ölçek parametresi } & (\mathrm{m} / \mathrm{s}) \\ \mathrm{P}\left(\mathrm{v}_{\mathrm{i}}\right) & =\text { Türbin güç eğrisinde hıza karşılık gelen güç değeri } & (\mathrm{MW}) \\ \mathrm{V} c \mathrm{O} & =\text { Rüzgâr türbininin devreden çıma hızı } & (\mathrm{m} / \mathrm{s}) \\ \mathrm{Vci} & =\text { Rüzgâr türbininin devreye girme hızı } & (\mathrm{m} / \mathrm{s}) \\ \mathrm{YEÜ} & =\text { Tek rüzgâr türbin için yıllık enerji üretimi } & (\mathrm{kWh}) \\ \mathrm{N}_{\mathrm{t}} & =\text { Toplam rüzgâr türbin sayısı } & (\mathrm{Adet}) \\ \mathrm{P}_{\mathrm{RES}} & =\text { RES için toplam yıllık üretim } & (\mathrm{MWh}) \\ \mathrm{C}_{\mathrm{RES}} & =\text { RES y1llk maliyeti } & (\text { Birimsiz) } \\ \left(X_{i}\right) & =\text { i. rüzgâr türbin x koordinatı } & (\mathrm{m}) \\ \left(Y_{\mathrm{j}}\right) & =\text { j. rüzgâr türbin y koordinatı } & (\mathrm{m})\end{array}$

\section{KAYNAKLAR (REFERENCES)}

[1] Dünya rüzgâr enerjisi derneği. "Rüzgâr kapasitesi". http://www.indea.org/2017-statistics/ (04.03.2018)

[2] M. Imal, M. Sekkeli, C. Yildiz, O.F. Kececioglu, Wind energy potential estimation and evaluation of electricity generation in Kahramanmaras, Turkey. Energy Education Science and Technology Part AEnergy Science and Research, 30 (2012) 661-672.

[3] M. Şekkeli, C. Yildiz, F. Karik, A. Sözen, Wind Energy in Turkey Electricity Market. Gazi Journal of Engineering Science, 1 (2015) 253-264.

[4] I. Karadöl, O.F. Keçecioğlu, H. Açıkgöz, M. Şekkeli, Examination of Solar and Wind Energy Hybrid System for Kahramanmaraş Region, Kahramanmaraş Sütçü İmam Üniversitesi Mühendislik Bilimleri Dergisi, 2 (2017) 89-96.

[5] K. Chen, M.X. Song, X. Zhang, S.F.Wang, Wind turbine layout optimization with multiple hub height wind turbines using greedy algorithm. Renewable Energy, 96 (2016) 676-686.

[6] M. Sekkeli, O.F. Keçecioğlu, H. Açıkgöz, C. Yıldız, A Comparison between theoretically calculated and actually generated electrical powers of wind turbines: A case study in Belen wind farm, Turkey. Academic Platform-Journal of Engineering and Science, 1 (2015) 41-47. 
[7] C. Y1ldı, M. Tekin, A. Gani, O.F. Kececioglu, H. Acikgoz, M. Sekkeli, Considering air density effect on modelling wind farm power curve using site measurements. Press Academia Procedia, 5 (2017) 420-430.

[8] J. Yang, R. Zhang, Q. Sun, H. Zhang, Optimal wind turbines micrositing in onshore wind farms using fuzzy genetic algorithm. Mathematical Problems in Engineering, 2015 (2015) 1-9.

[9] S. Brusca, R. Lanzafame, M. Messina, Wind turbine placement optimization by means of the Monte Carlo simulation method. Modelling and Simulation in Engineering, 2014 (2014) 1-8.

[10] Y. Eroglu, S.U. Seckiner, Wind farm layout optimization using particle filtering approach. Renewable Energy, 58 (2013) 95-107.

[11] J. Park, K.H. Law, Layout optimization for maximizing wind farm power production using sequential convex programming. Applied Energy, 151 (2015) 320-334.

[12] M.X. Song, K. Chen, Z.Y. He, X. Zhang, Optimization of wind farm micro-siting for complex terrain using greedy algorithm. Energy, 67 (2014) 454-459.

[13] G.Mosetti, C. Poloni, B. Diviacco, Optimization of wind turbine positioning in large windfarms by means of a genetic algorithm. Journal of Wind Engineering and Industrial Aerodynamics, 51 (1994) 105-116.

[14] M. Stevens, P. Smulders, The estimation of the parameters of the Weibull wind speed distribution for wind energy utilization purposes. Wind Engineering, 3 (1979) 132-145.

[15] T. Burton, N. Jenkins, D. Sharpe, E. Bossanyi, Wind energy handbook, John Wiley \&Sons, 2011.

[16] A. Kusiak, Z. Song, Design of wind farm layout for maximum wind energy capture. Renewable Energy, 35 (2010) 685-694.

[17] A. Emami, P. Noghreh, New approach on optimization in placement of wind turbines with in wind farm by genetic algorithms. Renewable Energy, 35 (2010) 1559-1564.

[18] J. Serrano-González, A.G. Gonzalez-Rodriguez, J. Castro-Mora, J. Riquelme-Santos , M. BurgosPayan, Optimization of wind farm turbines layout using an evolutive algorithm. Renewable Energy, 35 (2010) 1671-1681.

[19] J. Serrano-González, A.G. Gonzalez-Rodriguez, J. Castro-Mora, J. Riquelme-Santos , M. BurgosPayan, Overall design optimization of wind farms. Renewable Energy, 36 (2011) 1973-1982.

[20] B. Saavedra-Moreno, S. Salcedo-Sanz, A. Paniagua-Tineo, L. Prieto, A. Portilla- Figueras, Seeding evolutionary algorithms with heuristics for optimal wind turbines positioning in wind farms. Renewable Energy, 36 (2011), 2838-2844.

[21] S.A. Grady, M. Hussaini, M.M. Abdullah, Placement of wind turbines using genetic algorithms. Renewable Energy, 30, (2005), 259-270.

[22] G Marmidis, S Lazarou, E. Pyrgioti, Optimal placement of wind turbines in a wind park using Monte Carlo simulation. Renewable Energy, 33 (2008) 1455-1460.

[23] Y. Eroğlu, S.U. Seçkiner, Design of wind farm layout using ant colony algorithm. Renewable Energy, 44 (2012) 53-62.

[24] M. Wagner, J. Day, F. Neumann, A fast and effective local search algorithm for optimizing the placement of wind turbines. Renewable Energy, 51 (2013) 64-70.

[25] S. Rajper, I. J. Amin, Optimization of wind turbine micrositing: a comparative study. Renewable and Sustainable Energy Reviews, 16 (2012) 85-92. 
[26] J. Serrano-González, M. Burgos-Payan, J. M. Riquelme-Santos .Optimization of wind farm turbine layout including decision making under risk. IEEE Systems Journal, 6 (2012) 94-10.

[27] U.A. Ozturk, B.A. Norman, Heuristic methods for wind energy conversion system positioning. Electric Power Systems Research, 70 (2004) 179-185.

[28] C.G. Justus, W.R. Hargraves, A. Mikhail, D. Graber, Methods for estimating wind speed frequency distributions. Journal of Applied Meteorology, 17 (1978) 350-353.

[29] J.F Manwell, J.G McGowan, A.L. Rogers, Wind Energy Explained- Theory Design and Application, John Wiley \& Sons Ltd, University of Massachusetts, Amherst, 2002.

[30] Y.M. Bulut, E. Açıkkalp, Rüzgar Enerjisi Potansiyelinin Hesaplanmasında Parametre Tahmin Yöntemlerinin İncelenmesi, Gazi Üniversitesi Fen Bilimleri Dergisi Part C: Tasarım ve Teknoloji 1:2, (2013) 49-54.

[31] Bonus 2MW Turbine (2018), https://en.wind-turbine-models.com/turbines/121-bonus-b76-2000 (04.03.2018).

[32] D. Goldberg, Genetic Algorithms in Search Optimization and Machine Learning, Wesley Professional, Boston, 1989. 